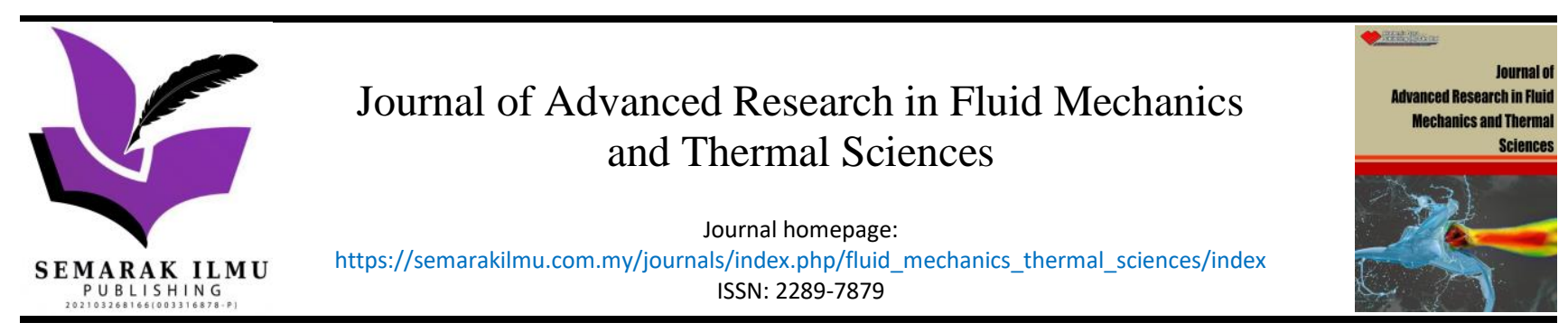

\title{
Thermal Behaviour of Nanocomposite Phase Change Material for Solar Thermal Applications
}

\author{
Akram Fadhl Al-Mahmodi ${ }^{1}$, Lukmon Owolabi Afolabi ${ }^{1,}{ }^{*}$, Mohammed Ghaleb Awadh ${ }^{1}$, Mohammad \\ Faizal Mohideen Batcha ${ }^{1}$, Nigali Zamani ${ }^{1}$, Norasikin Mat Isa ${ }^{1}$, Djamal Hissein Didane ${ }^{1}$ \\ 1 Center for Energy \& Industrial Environment Studies (CEIES), Faculty of Mechanical and Manufacturing Engineering, Universiti Tun Hussein Onn \\ Malaysia, Batu Pahat, 86400 Johor, Malaysia
}

ARTICLE INFO

\section{Article history:}

Received 4 August 2021

Received in revised form 20 September 2021

Accepted 21 September 2021

Available online 30 October 2021

\section{Keywords:}

Thermal Energy Storage; Phase Change Material; Nanocomposite; Solar Thermal Collector

\section{ABSTRACT}

The use of solar thermal technologies has shown great prospects towards solar energy conversion into more useful forms of energy and has increasingly expanded solar thermal technology applications. However, the inability to properly store the excess solar energies during peak hours and demands have limited many of their applications. The integration of thermal energy storage (TES) systems with thermal technologies have increased the solar thermal technology performance but the poor thermal characteristics exhibited by phase change materials (PCM) limited the system overall performance. The enhancement of PCM properties by nonadditive have shown increased material performance in TES application and thereby extending the use of solar thermal technology application. Given this narrative and identifies literature gaps, the present study investigated experimentally the enhancement of paraffin PCM using nonadditive metallic of different types and concentrations and analysed their thermal behaviours. The results showed that $\mathrm{Cu}$ /paraffin PCM nanocomposites had good thermal reliability in proposed applications even after 150 thermal cycles under different temperatures. Moreover, thermal conductivity was improved significantly as an enhancement of $39 \%$ was reported when adding $2.5 \%$ of $\mathrm{Cu}$ nanoparticles. While specific heat and thermal diffusivity has been enhanced by $16 \%$ and $9 \%$, respectively compared to pure paraffin. The obtained results were compared with different theoretical models such as Maxwell mode, Hamilton Crossover model, Jeffery model, and Bruggeman model. The calculated values show a good agreement with experimental ones. As a result, the prepared $\mathrm{Cu}$ /Paraffin nanocomposite PCM shows significant promise in thermal energy storage application due to its favourable phase change temperature, comparatively large latent heat, enhanced thermal conductivity and high thermal reliability and conversion. The proposed nanocomposite PCM can be used in many applications such as building materials to reduce interior temperature swings, enhance thermal comfort, and conserve electricity consumption.

\footnotetext{
* Corresponding author.

E-mail address: afoolabs@gmail.com; afoolabs@uthm.edu.my
}

https://doi.org/10.37934/arfmts.88.2.133146 


\section{Introduction}

Energy is available on our planet from the sun. The sun is considered as the most important energy source found on our planet earth and every day it emits a huge load of energy which can power everything on the earth. Sun is being used as a fuel in renewable energy solar thermal systems that absorbs and converts irradiation into usable energy [1-3]. Solar thermal is clean and is used in buildings sectors as a source of heat supply. Solar collector captures the irradiation comes from the sun and passed to its working fluid in form of heating water inside the storage tank for domestic hot water heating. After accumulating the thermal energy by solar collectors there was a need for storage that Solar collectors face a challenge of capturing solar energy during rainy and cloudy days when the irradiation of the sun is too low leading to a noticeable drop in efficiency of the solar system which depends mainly on solar radiation [2-3]. Generally, renewable energy sources are unable to give constant power, therefore, is essential to overcome this problem by designing efficient energy storage as the heat could be stored to use after at night or even cloudy days.

The basic purpose of energy storage systems is to collect energy when the production is higher than demand and make the energy usable when there is no production [3]. Thermal energy storage is a technology that keeps thermal energy using the change in temperature of the storage medium either by heating, cooling or for power generation, Thermal energy storage can minimize energy consumption, emissions and peak demand when it is working on improving the overall system efficiency simultaneously [4, 5]. Thermal energy storage technology uses are sensible heat, latent heat and thermochemical. Among these types, latent heat storage using phase change material (PCM) is considered an effective technique due to advantageous characteristics during the phase change process which results in storage density and nearly isothermal operating characteristics [6, 8]. Thermal energy storage technologies based on the phase change material PCM are identified as one of the advanced technologies for improving the environmental utilization efficiency of renewable energy because they can store energy with high density and a narrow temperature range beyond a constant phase change temperature $[8,9]$. However, there is a limitation on their use in thermal transfer applications due to their low thermal conductivity and subcooling. Hence, nanomaterials are being presented as enhancement tools to be used in PCM to improve their thermophysical properties in general and thermal conductivity in particular [10].

Because of their significant influence on PCM thermal characteristics, nanoparticles have lately been explored to improve the performance of thermal storage systems. The thermal conductivity of the PCM can be enhanced by distributing high thermal conductive particles into it to overcome the issue of low thermal conductivity [11]. Such a mixture is known as composite phase change material. Composite materials are materials containing a PCM and at least one additional material that works on improving at least one of the PCM characteristics. In most cases, this is handling of the PCM, but compounds can also improve heat transfer through the addition of materials with large thermal conductivity [12]. The benefit of nanoparticles is that they are incredibly tiny. As a result, they act like fluids and do not clog pipes during flow. In general, nanocomposite material boasts high stability, high thermal conductivity and the capability to keep solid forms during the phase transition process [13]. 


\section{Materials and Methods}

\subsection{List of Materials}

Paraffin PCM, Cu nanoparticle, round bottom flask, beaker, pipit tube, filter paper, and surfactant. Paraffin was purchased from SOREPCO SDN BHD (Malaysia, Sarawak) with 100\% purity and melting temperature of $58-60{ }^{\circ} \mathrm{C}$. And the $\mathrm{Cu}$ nanoparticle with an average particle diameter of $25 \mathrm{~nm}$ and purity $\geq$ of $98 \%$ was purchased from BT SCIENCE SDN BHD (Malaysia, Selangor). All chemicals were used without any further purification.

\subsection{List of Equipment}

Bath sonicator, magnetic stirrer, $250 \mathrm{ml}$ beaker, Scanning electron microscopy (SEM), Thermogravimetric analyser (TGA), thermal constant analyser, thermocouple/thermometer, hotplate, particle size analyser, ultrasonication and environmental test chamber.

\subsection{Method of Preparation and Synthesis}

A two-step method as shown in Figure 1 will be adopted for the synthesis of paraffin PCM nanocomposite. The paraffin wax and different weight fractions of $\mathrm{Cu}$ nanoparticles. Pure Paraffin wax, 0.5 percent, 1.0 percent, 1.5 percent, and 2.0 percent Nano copper weight percentages were used in the current experimental research. The standard sample size for this experiment was $150 \mathrm{~g}$ of copper-PCM nanocomposite. To begin, a $250 \mathrm{~mL}$ beaker was filled with $149.25 \mathrm{~g}$ of Paraffin wax. Second, $0.75 \mathrm{~g}$ of nano copper was distributed in the Paraffin wax, which is comparable to 0.5 percent of the copper-PCM nanocomposite weight. Finally, an electrical ultrasonication mechanism keeps the temperature of the combination liquid at $75^{\circ} \mathrm{C}$. The ultrasonication device will provide heating and vibration at a frequency of $40 \mathrm{kHz}$, with vibrational energy produced at this frequency assisting in the uniform dispersion of nanoparticles into the base liquid PCM. The combination was ultrasonicated for four hours to reduce nano copper agglomeration by breaking the agglomerated particles down to individual nano size and dispersed as suspended particles inside the liquid PCM. The hot liquid was set aside for four hours to cool to room temperature. The same procedure was repeated for the $1 \%, 1.5 \%$ and $2 \%$ weight ratio of copper-PCM nanocomposites samples.

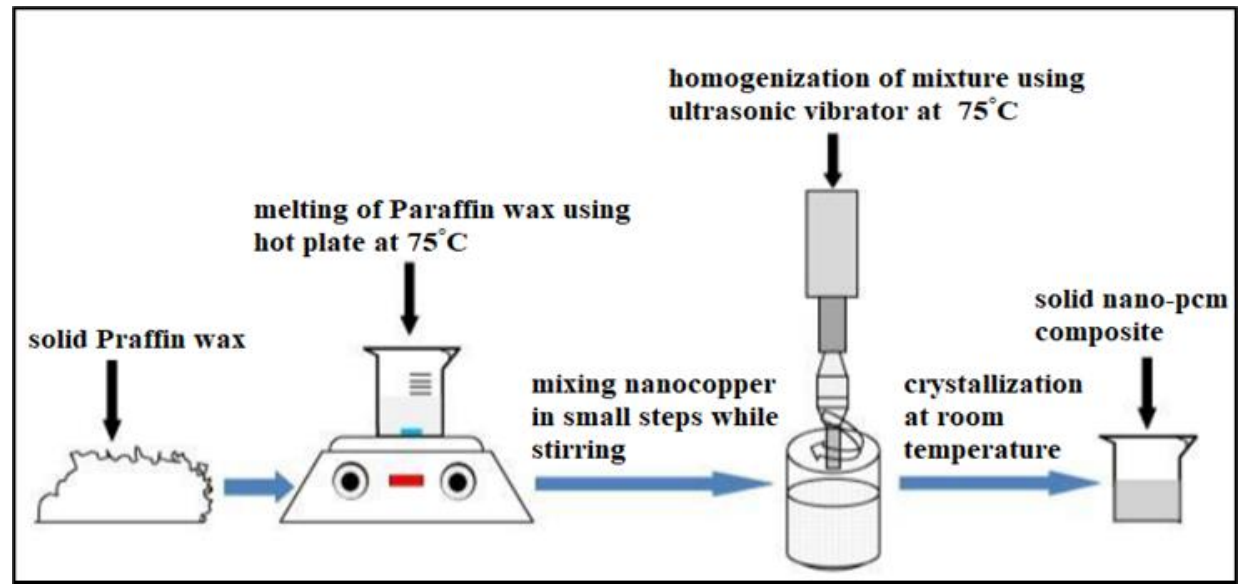

Fig. 1. Preparation steps of nanocomposite PCM 


\subsection{Characterization}

Thermophysical properties of the MOKO, DKO, PKO, CKO, and MKO was carried to determine the melting and boiling point, thermal conductivity, specific heat, thermal diffusivity, density, and viscosity. These are essential fluid properties that determine suitability for heat transfer fluids. Many reports [14] on the characterization of heat transfer fluids have been presented with fewer studies on biofluids [13].

\subsection{Thermal behaviour}

Measurement of heating temperature and the heating cycle was adopted as parameters of the investigation. The heating temperature used was $120 \mathrm{oC}$, while 100 and 200 heating cycles were adopted was thermal degradation analysis. For each heating cycle, the oils are heated from ambient temperature to $120 \mathrm{oC}$, then allowed to cool till ambient temperature to complete one cycle. The process was repeated 100 and 200 heating cycles, with each taken 20 mins.

\section{Result and Discussion}

\subsection{Compatibility of Composite PCM}

The dispersion stability of nanocomposites was verified using photo-image analysis in this study. If the dispersion stability of the prepared nanosuspension is poor, the nanoparticles will quickly agglomerate into flocs and precipitate out. The nanoparticle suspension with a good dispersion effect is very stable, without obvious flocculation and precipitation, and the structure is relatively stable. In this experiment, different concentrations $(0.5 \%, 1 \%, 1.5 \%, 2 \%$ and $2.5 \%)$ of copper additive/paraffin PCM were prepared. Figure 2 shows the images state of pure PCM paraffin and different proportions of $\mathrm{Cu}$ nanocomposite PCM. It can be seen from the figure that as more copper nanoparticles are added to the paraffin, the area of the nanocomposite PCM becomes darker. The black area corresponds to the unsaturated copper nanoparticles, the grey areas with different shades represent the saturated copper nanoparticles, and the white area is the excess paraffin. The figure shows that the nanocomposite PCM has good dispersion stability.

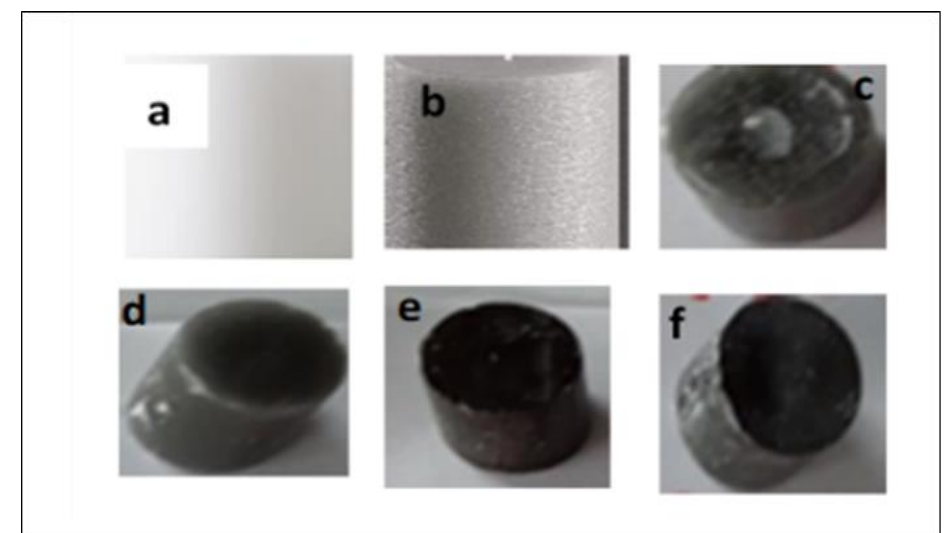

Fig. 2. Photo-image of $P C M$-paraffin wax and $P C M$ composite (a) PCM paraffin, (b) PCM nanocomposite $0.5 \% \mathrm{wt}$, (c) PCM nanocomposite $1 \% \mathrm{wt}$, (d) PCM nanocomposite $1.5 \% \mathrm{wt}$, (e) PCM nanocomposite $2 \% \mathrm{wt}$ and (f) PCM nanocomposite $2.5 \% \mathrm{wt}$ 


\subsection{Thermophysical Properties}

The material thermophysical properties comprise of specific heat capacity, thermal conductivity, thermal diffusivity, density, coefficient of linear thermal expansion, the heat of vaporization, and heat of combustion. Material thermophysical magnitudes of the paraffin PCM and PCM nanocomposite are presented and discussed below.

\subsubsection{Thermal conductivity of composite PCMs}

The rate of energy storage and release is highly dependent on the thermal conductivity of PCMs. Thermal conductivity is a crucial parameter for PCM because it reflects the material's heat transfer rate. In addition, high thermal conductivity can faster heat absorption which results in increasing the thermal performance of PCM. In this study, Cu nanoparticles were added as thermal conductivity enhancers to paraffin PCM composite. Figure 3 shows the thermal conductivity values of PCMs as a function of nanoparticle concentration. It shows that the thermal conductivity of PCMs is enhanced gradually with the concentration of Cu nanoparticles. Thermal conductivities of PCM composite with $0.5,1,1.5,2$ and 2.5 wt.\% of $\mathrm{Cu}$ are $0.2483,0.3189,0.3227,0.3301,0.3398$ and $0.3492 \mathrm{~W} / \mathrm{m} \mathrm{K}$, respectively

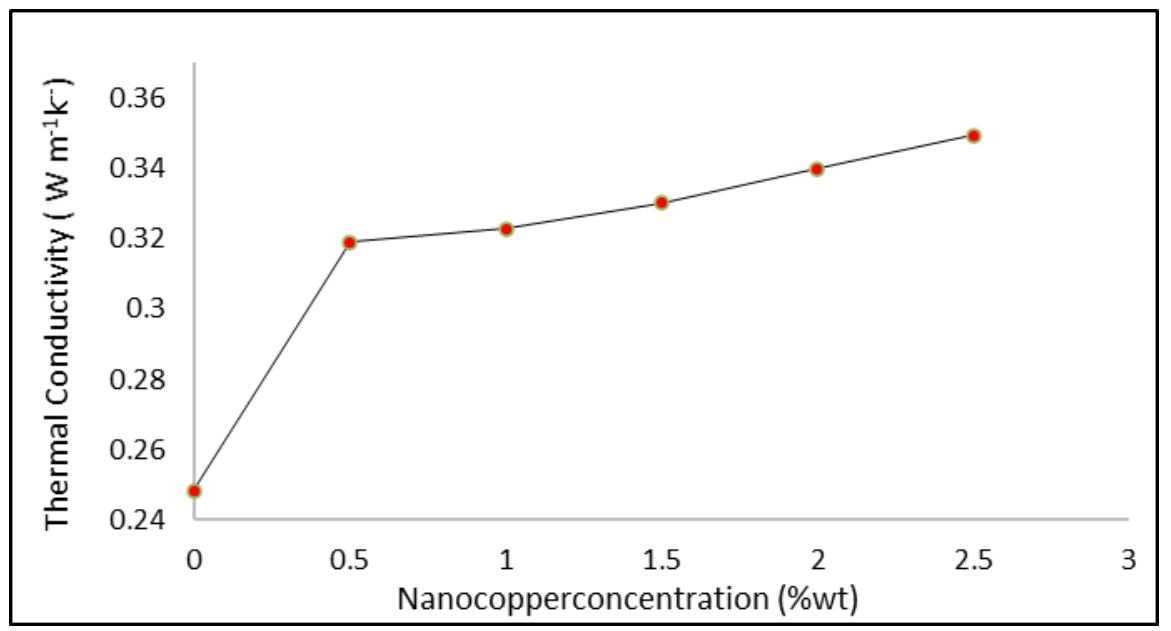

Fig. 3. Thermal conductivity Vs Volume Concentration of Cu nanoparticle in Paraffin PCM at $30^{\circ} \mathrm{C}$

\subsubsection{Melting point}

The selection of suitable phase change substances in specific applications mostly depends on their melting point to ensure the heat absorption or release at the right temperature. It is stated that, by adding $\mathrm{Cu}$ nanoparticles, the melting of paraffin wax becomes faster as the first sample need more heat supplies to melt completely the paraffin wax compare to sample 2,3,4 and sample 5 . As it can be observed from Figure 4, adding 0.5, 1, 1.5, 2 and 2.5 wt.\% of Cu resulted in decreasing the melting point to $53,51,49,48,47$ and $47^{\circ} \mathrm{C}$, respectively. The reduction in the melting point of the composite PCMs confirmed the improvement in the thermal conductivity of the paraffin. Noteworthy that the nanocomposite PCM rapidly absorb heat supplied from a heat source compared with pure paraffin as PCM. 


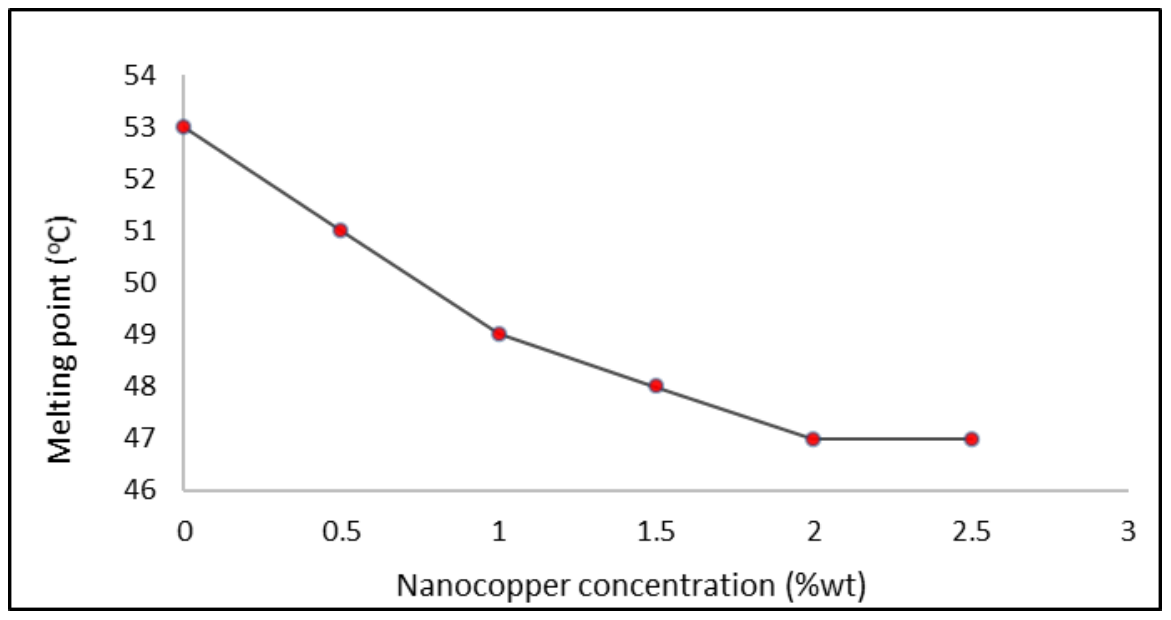

Fig. 4. Melting point Vs Volume Concentration of Cu nanoparticle in Paraffin $\mathrm{PCM}$ at $30^{\circ} \mathrm{C}$

\subsubsection{Specific heat}

The specific heat capacity is essential thermal property of a material. Figure 5 shows that, as nanoparticles embedded in the nano-PCM composite increased, the specific heat of the composite decreased. At 0.5, 1, 1.5, 2 and 2.5 wt.\% concentration of $\mathrm{Cu}$ nanoparticles, the melting point reduced by $0.1742,0.1549 .0 .1482$. 0.1433 and $0.1401 \mathrm{MJ} / \mathrm{m}^{3} \mathrm{~K}$, respectively. The mechanism for increasing specific heat at elevated temperatures can be described due to vibrational, rotational and translation of molecules at higher temperatures.

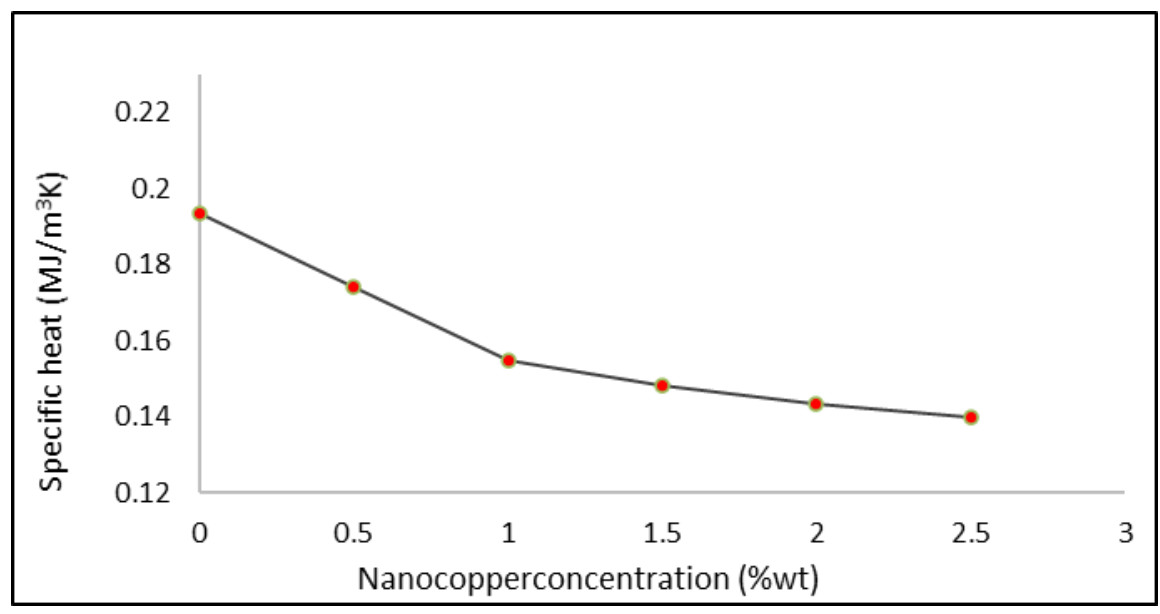

Fig. 5. Specific Heat Vs Volume Concentration of Cu nanoparticle in Paraffin $\mathrm{PCM}$ at $30^{\circ} \mathrm{C}$

\subsubsection{Thermal diffusivity}

Thermal diffusivity is the rate at which temperature changes occur in a material. The higher the value of thermal diffusivity the quicker the material will reach temperature equilibrium with its environment. The lower conductivity and higher heat storage capacity of the PCM materials results in reduced thermal diffusivity effectiveness of the PCM. As it can be observed from Figure 6, the thermal diffusivity of composite PCMs with $0.5,1,1.5,2$ and 2.5 wt.\% of $\mathrm{Cu}$ are 1.5621, 1.8243, $1.9281,2.1532$, and $2.0172 \mathrm{~W} / \mathrm{m}^{2} / \mathrm{s}$, respectively. The result showed that increasing the concentration of $\mathrm{Cu}$ nanoparticles to the paraffine PCM results in increasing the thermal diffusivity. 


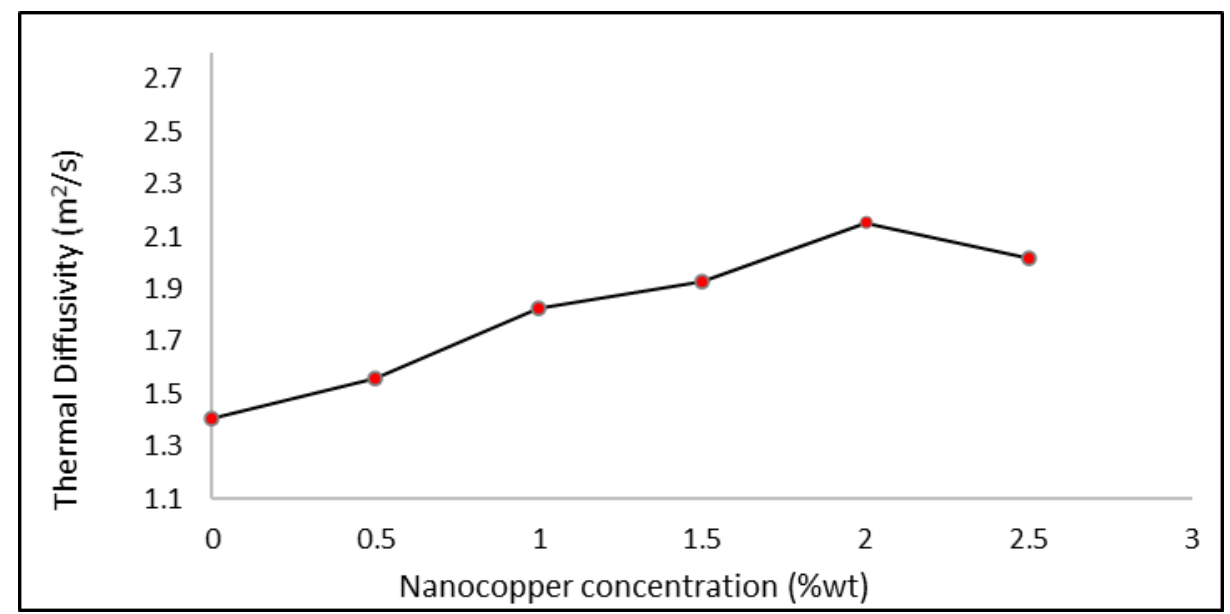

Fig. 6. Thermal diffusivity Vs Volume Concentration of $\mathrm{Cu}$ nanoparticle in Paraffin PCM at $30^{\circ} \mathrm{C}$

\subsubsection{Density}

Density is an important thermophysical property for composite materials. Figure 7 shows the density of pure PCM and nanocomposite PCM. Based on the figure, the density of PCM composite increase with increasing of the portion of nanoparticles added to the PCM nanocomposite. Addition of $0.5,1,1.5,2$ and $2.5 \mathrm{wt}$.\% concentration of $\mathrm{Cu}$ nanoparticles, caused the density to increase by $963.18,1045.23,1256.24,1289.61$, and $1301.82 \mathrm{Kg} / \mathrm{m}^{3}$, respectively. The results demonstrated that incorporating nanoparticles increased the density of the composite. Generally, density is an important factor that affects the efficiency of PCM as conductivity has a linear relationship with density. As the density of the composite material increases, the thermal conductivity of the composite material increases. This outcome has great significance for the production and application of composite PCM.

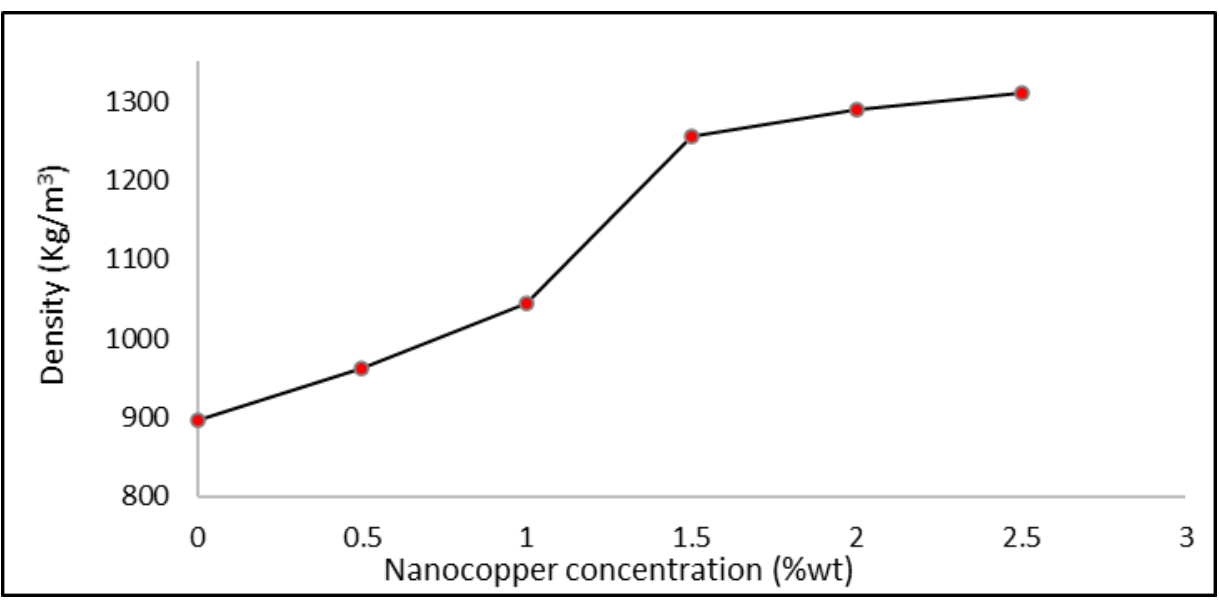

Fig. 7. Density Vs Volume Concentration of Cu nanoparticle in Paraffin PCM at $30{ }^{\circ} \mathrm{C}$

\subsection{Comparison of the Present Study with Literature}

Shin, Banerjee studied the effect of adding $\mathrm{SiO}_{2}$ nanoparticles in eutectic of lithium carbonate to obtain a high-temperature nanocomposite. The study shows that with the adding of $1 \%$ concentration by weight the specific heat was enhanced by $5 \sim 15 \%$ and the thermal diffusivity was 
enhanced by $25 \sim 28 \%$, respectively. The corresponding effective thermal conductivity of the nanocomposite was calculated to be enhanced by $35 \sim 45 \%$ compared with that of the pure PCM while the density of nanocomposite had a slight increase of $0.8 \%$. In addition, Warzoha et al., study the effect of graphite nanofibers on the thermal properties of paraffin PCM.

Table 1

Comparison of the present study with other authors percentage (\%), enhancement

\begin{tabular}{|c|c|c|c|c|}
\hline $\begin{array}{l}\text { Thermophysical } \\
\text { properties }\end{array}$ & Present study & [15] & [16] & [17] \\
\hline $\begin{array}{l}\text { Thermal } \\
\text { Conductivity } \\
\lambda / \mathrm{Wm}^{-1} \mathrm{k}^{-1} \\
\text { at } 30^{\circ} \mathrm{C}\end{array}$ & $\begin{array}{l}\text { 2-Step method of } \\
\text { preparation. } 2.5 \% w t \text {, } \\
\text { Paraffin/Cu- } \\
\text { nanoparticle. } \\
\text { 39\% enhancement } \\
\text { No surfactant added }\end{array}$ & $\begin{array}{l}\text { Two-step liquid } \\
\text { method } \\
\mathrm{SiO}_{2} \text { nanocomposite } \\
1 \% \text { wt } \mathrm{Cp} \\
\text { nanocomposite } \\
35-45 \% \text { enhancement }\end{array}$ & $\begin{array}{l}\text { steady-state } \\
\text { method } \\
\text { graphite } \\
\text { nanofibers } \\
12 \% \text { wt } \\
\text { Paraffin/GNF } \\
180 \% \\
\text { enhancement }\end{array}$ & $\begin{array}{l}\text { Two-Step method. } \\
3 \% \text { wt eutectic } \\
\text { PCM/ nano- } \\
\text { graphene } \\
44.9 \% \\
\text { enhancement }\end{array}$ \\
\hline $\begin{array}{l}\text { Specific Heat } \\
\mathrm{J} /(\mathrm{kg} . \mathrm{K} \\
\text { at } 30{ }^{\circ} \mathrm{C}\end{array}$ & $\begin{array}{l}\text { 2-Step method of } \\
\text { preparation. } 2.5 \% \text { wt, } \\
\text { Paraffin/Cu- } \\
\text { nanoparticle. } \\
16 \% \text { enhancement } \\
\text { No surfactant added }\end{array}$ & $\begin{array}{l}\text { Two-step liquid } \\
\text { method } \\
\mathrm{SiO}_{2} \text { nanocomposite } \\
1 \% \text { wt } \mathrm{Cp} \\
\text { nanocomposite } \\
\text { 5-15\% enhancement }\end{array}$ & $\begin{array}{l}\text { steady-state } \\
\text { method } \\
\text { graphite } \\
\text { nanofibers } \\
12 \% \text { wt } \\
\text { Paraffin/GNF } \\
14 \% \text { enhancement }\end{array}$ & $\begin{array}{l}\text { Two-Step method. } \\
3 \% \text { wt eutectic } \\
\text { PCM/ nano- } \\
\text { graphene } \\
35.6 \% \\
\text { enhancement }\end{array}$ \\
\hline $\begin{array}{l}\text { Thermal } \\
\text { Diffusivity } \\
\text { at } 30^{\circ} \mathrm{C}\end{array}$ & $\begin{array}{l}\text { 2-Step method of } \\
\text { preparation. } 2.5 \% \text { wt, } \\
\text { Paraffin /Cu- } \\
\text { nanoparticle. } \\
9 \% \text { enhancement } \\
\text { No surfactant added }\end{array}$ & $\begin{array}{l}\text { Two-step liquid } \\
\text { method } \\
\mathrm{SiO}_{2} \text { nanocomposite } \\
1 \% \text { wt } \mathrm{Cp} \\
\text { nanocomposite } \\
25-28 \% \text { enhancement }\end{array}$ & $\begin{array}{l}\text { steady-state } \\
\text { method } \\
\text { graphite } \\
\text { nanofibers } \\
12 \% \text { wt } \\
\text { Paraffin/GNF } \\
253 \% \\
\text { enhancement }\end{array}$ & $\begin{array}{l}\text { Two-Step method. } \\
3 \% \text { wt eutectic } \\
\text { PCM/ nano- } \\
\text { graphene } \\
24.16 \% \\
\text { enhancement }\end{array}$ \\
\hline $\begin{array}{l}\text { Density }(\rho) \\
\mathrm{Kg} / \mathrm{m}^{3} \\
\text { at } 30^{\circ} \mathrm{C}\end{array}$ & $\begin{array}{l}\text { 2-Step method of } \\
\text { preparation. } 2.5 \% \text { wt, } \\
\text { Paraffin/Cu- } \\
\text { nanoparticle. } \\
3 \% \text { enhancement } \\
\text { No surfactant added }\end{array}$ & $\begin{array}{l}\text { Two-step liquid } \\
\text { method } \\
\mathrm{SiO}_{2} \text { nanocomposite } \\
1 \% \text { wt } \mathrm{Cp} \\
\text { nanocomposite } \\
0.8 \% \text { enhancement }\end{array}$ & $\begin{array}{l}\text { steady-state } \\
\text { method } \\
\text { graphite } \\
\text { nanofibers } \\
12 \% \text { wt } \\
\text { Paraffin/GNF } \\
1.48 \% \\
\text { enhancement }\end{array}$ & $\begin{array}{l}\text { Two-Step method. } \\
3 \% \text { wt eutectic } \\
\text { PCM/ nano- } \\
\text { graphene } \\
3.62 \% \\
\text { enhancement }\end{array}$ \\
\hline
\end{tabular}

The study showed that, by adding $12 \%$ of graphite nanofiber, the thermal conductivity improved significantly to reach $180 \%$ enhancement. The same high improvement occurred for the thermal diffusivity with an enhancement of $253 \%$. The specific heat of nanocomposite reduced to a value of 1.9 (J/g.K) which represents $14 \%$ enhancement compared to pure paraffine. Density also had a little enhancement with increasing of $1.48 \%$ compared to pure PCM. Another study was carried by Saeed, et al., to examine the effect of adding Nano-graphene to form eutectic PCM. Based on the study, the poor thermal conductivity was increased by about $44.9 \%$ with a $3 \%$ wt additive of nano-graphene. Moreover, the specific heat and thermal diffusivity were improved to an enhancement of $35.6 \%$ and $24.16 \%$, respectively. Comparing the present study with previous works, the thermal conductivity of the present study is quite high, however, the mass ratio was small compared to other studies which 
explain the high thermal conductivity achieved as the mass volume of nanoparticles has a linear relation with thermal conductivity improvement. In addition, the specific heat of the present study shows a competitive value with an enhancement of $16 \%$. Lastly, the density of nanocomposite in the present study shows a noticeable enhancement of $3 \%$ compared to pure paraffin PCM.

\subsection{Thermal Reliability}

It is important to have good thermal reliability for composite PCMs. Thermal reliability refers to whether the thermal storage performance of composite PCMs changes after repeated heat storage and release [19-20]. The thermal properties of excellent composite PCMs should not change or only have little change after long-term use. Therefore, the thermal reliability of the developed nanocomposites PCM is determined using an accelerated heating cycle at different heating temperatures 60,100 and $120^{\circ} \mathrm{C}$. Table 2 represents the thermophysical properties at $2.5 \% \mathrm{wt}$. of Cu PCM Nanocomposite after 50,100 and 150 heating cycles.

\section{Table 2}

Thermal reliability analysis of PCM paraffin and PCM nanocomposite

\begin{tabular}{|c|c|c|c|c|c|c|c|c|c|}
\hline \multirow{2}{*}{$\begin{array}{l}\text { Thermophysical } \\
\text { Properties }\end{array}$} & \multicolumn{9}{|c|}{ 2.5\% wt. Cu PCM Nanocomposite } \\
\hline & $\begin{array}{l}50 \\
\text { heating } \\
\text { cycle at } \\
\text { heating } \\
\text { temp } \\
60^{\circ} \mathrm{C}\end{array}$ & $\begin{array}{l}100 \\
\text { heating } \\
\text { cycle at } \\
\text { heating } \\
\text { temp } \\
60^{\circ} \mathrm{C}\end{array}$ & $\begin{array}{l}150 \\
\text { heating } \\
\text { cycle at } \\
\text { heating } \\
\text { temp } \\
60^{\circ} \mathrm{C}\end{array}$ & $\begin{array}{l}50 \\
\text { heating } \\
\text { cycle at } \\
\text { heating } \\
\text { temp } \\
100^{\circ} \mathrm{C}\end{array}$ & $\begin{array}{l}100 \\
\text { heating } \\
\text { cycle at } \\
\text { heating } \\
\text { temp } \\
100^{\circ} \mathrm{C}\end{array}$ & $\begin{array}{l}150 \\
\text { heating } \\
\text { cycle at } \\
\text { heating } \\
\text { temp } \\
100^{\circ} \mathrm{C}\end{array}$ & $\begin{array}{l}50 \\
\text { heating } \\
\text { cycle at } \\
\text { heating } \\
\text { temp } \\
120^{\circ} \mathrm{C}\end{array}$ & $\begin{array}{l}100 \\
\text { heating } \\
\text { cycle at } \\
\text { heating } \\
\text { temp } \\
120^{\circ} \mathrm{C}\end{array}$ & $\begin{array}{l}150 \\
\text { heating } \\
\text { cycle } \\
\text { heating } \\
\text { temp } \\
120^{\circ} \mathrm{C}\end{array}$ \\
\hline $\begin{array}{l}\text { Thermal } \\
\text { Conductivity } \\
\lambda / \mathrm{Wm}^{-1} \mathrm{k}^{-1} \\
30^{\circ} \mathrm{C}\end{array}$ & 0.3382 & 0.3323 & 0.3303 & 0.3298 & 0.3245 & 0.3205 & 0.3265 & 0.3222 & 0.3201 \\
\hline $\begin{array}{l}\text { Specific Heat } \\
\mathrm{J} /(\mathrm{kg} . \mathrm{K} \\
\text { at } 30{ }^{\circ} \mathrm{C}\end{array}$ & 0.1378 & 0.1342 & 0.1315 & 0.1343 & 0.1315 & 0.1288 & 0.1317 & 0.1311 & 0.1302 \\
\hline $\begin{array}{l}\text { Thermal } \\
\text { Diffusivity } \\
\text { at } 30^{\circ} \mathrm{C}\end{array}$ & 2.0061 & 2.0025 & 2.0003 & 2.0113 & 2.0125 & 2.0186 & 2.0098 & 2.0147 & 2.0193 \\
\hline $\begin{array}{l}\text { Density }(\rho) \\
\mathrm{Kg} / \mathrm{m}^{3} \\
\text { at } 30{ }^{\circ} \mathrm{C} \\
\mathrm{Kg} / \mathrm{m}^{3}\end{array}$ & 1301.82 & 1327.04 & 1335.57 & 1292.11 & 1301.82 & 1322.35 & 1328.67 & 1333.16 & 1342.02 \\
\hline
\end{tabular}

From 4.3, the thermal conductivity of $2.5 \%$ wt. Cu PCM Nanocomposite at $60{ }^{\circ} \mathrm{C}$ after 50,100 , and 150 heating cycle varied by $0.3382,0.3323$ and $0.3303 \mathrm{~W} /(\mathrm{m} \mathrm{K})$, respectively. The effect of heating cycle number on the thermal behaviour of the composite PCM is observed. With increasing the temperature to $120{ }^{\circ} \mathrm{C}$, the thermal conductivity of nanocomposite PCM still shows good reliability as the thermal conductivity after 50,100 , and 150 heating cycles is stated as $0.3265,0.3222$ and $0.3201 \mathrm{~W} / \mathrm{m} \mathrm{K}$, respectively. There is no significant change in the thermal conductivity after 150 heating cycling and temperature up to $120^{\circ} \mathrm{C}$ which proves that nanocomposite PCM has good thermal reliability. Moreover, the specific heat of nanocomposite PCM changed by $0.1378,0.1342$ and $0.1315 \mathrm{~J} /$ (kg.K). whereas the value of thermal diffusivity slightly changed as $2.0061,2.0025$, and $2.0003 \mathrm{~W} / \mathrm{m} 2 / \mathrm{s}$, respectively after repeated 50,100 , and 150 heating cycles. These results are almost negligible for thermal energy storage applications. 


\subsection{Differential Scanning Calorimetry (DCS) Analysis}

Phase change temperature and latent heat are key performances that determine the thermal storage capacity contributing to indoor temperature in thermal storage application [18, 21]. DSC analysis was conducted to investigate the influence of $\mathrm{Cu}$ addition on thermal properties such as melting temperature and the latent heat storage capacity of paraffin and the composite PCMs. The DSC analysis results for Nanocomposite PCM is shown in Figure 8.

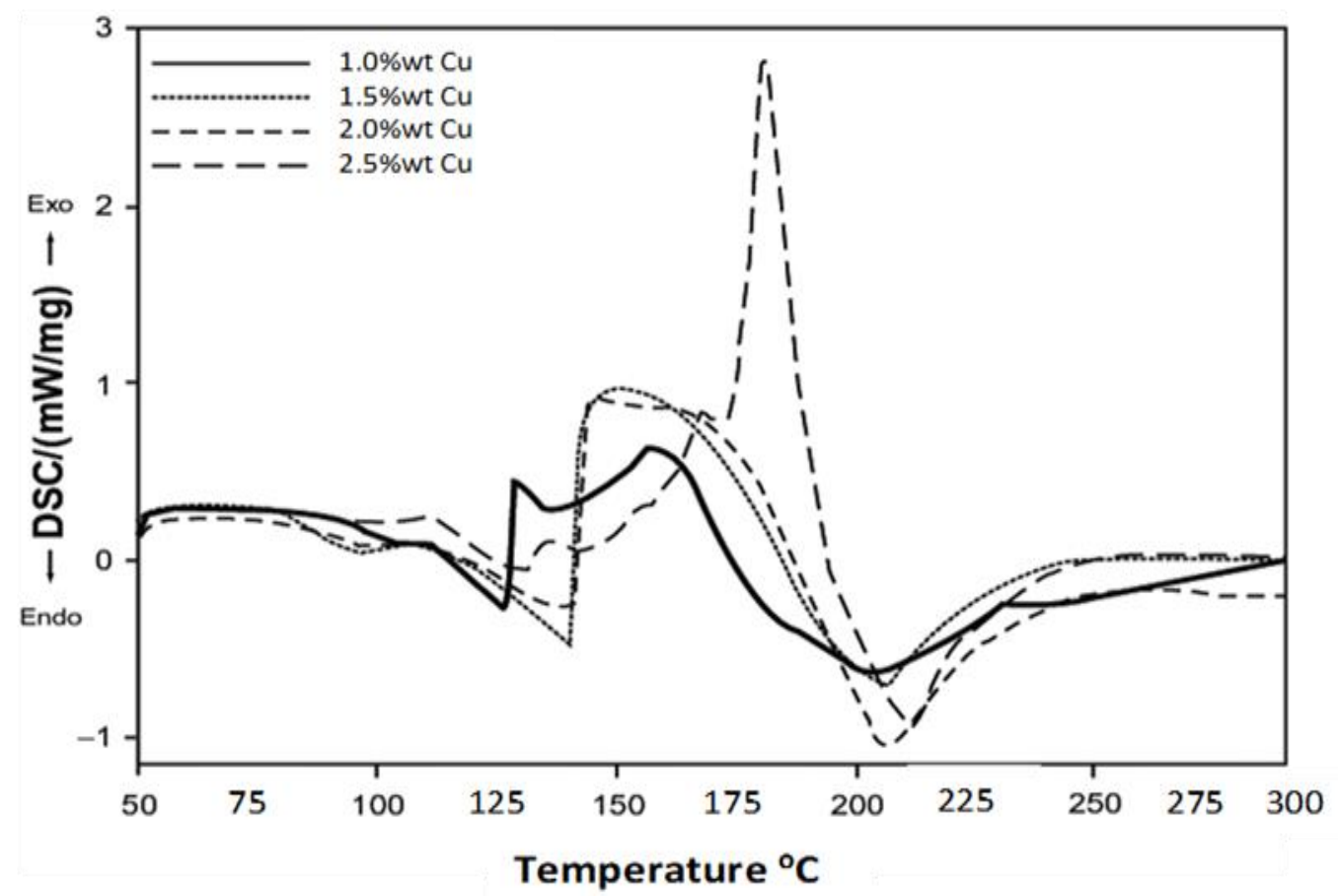

Fig. 8. DSC thermal analysis for PCM nanocomposite

From the DSC curves, the first small peaks are due to solid-to-solid phase transition in the phase peak, while the second-high peak is due to solid to liquid transition. Adding more concentration of $\mathrm{Cu}$, increasing the melting temperature to $135.32{ }^{\circ} \mathrm{C}, 143.97{ }^{\circ} \mathrm{C}, 151.23{ }^{\circ} \mathrm{C}$ and $189.32{ }^{\circ} \mathrm{C}$ for $1.0 \%$ Paraffin/Cu, 1.5\% Paraffin/Cu, 2.0\% Paraffin/Cu and 2.5\% Paraffin/Cu, respectively. The results show that the nano $\mathrm{Cu}$ has acted as a nucleation agent and help to increase the rate of crystallization and reduce the supercooling effect of the paraffin wax. The nano $\mathrm{Cu}$, also, effectively stabilized the temperature fluctuation of the heated surface to reduce the thermal resistance of melting and solidification. Table 3 shows the melting and crystallization behaviour for pure PCM and nanocomposite PCM.

It is important to analyze the materials onset temperature and its peaks during the melting and crystallization process to quantify its thermal behaviour rate during their practical applications. The phase change temperature is divided into starting, peak and ending temperatures. The starting and ending temperatures are the temperatures at the intersection of the extrapolated baseline and the tangents to the DSC curve drawn at the inflection points to the left and right side of the peak while the peak temperature is the temperature at the peak point of the DSC curve. In the heating cycle, melting temperatures of paraffin composites decrease with the increase of $\mathrm{Cu}$ nanoparticles since $\mathrm{Cu}$ cause heterogeneous nucleation and the formation of crystalline regions by changing the arrangement of polymer chains. In the cooling cycles, crystallization temperature decreases by the addition of $\mathrm{Cu}$ nanoparticles due to the random dispersion of re-stacked $\mathrm{Cu}$ nanoparticles and the 
limitations in the mobility of polymer chains. However, there are no significant differences in melting and crystallization temperature values of $0.5 \mathrm{wt} \%, 1 \mathrm{wt} \%, 1.5 \mathrm{wt} \%$, and $2.0 \mathrm{wt} \% \mathrm{Cu} \mathrm{PCM}$ Nanocomposite composites.

\section{Table 3}

Melting and crystallization behaviour of nanocomposite

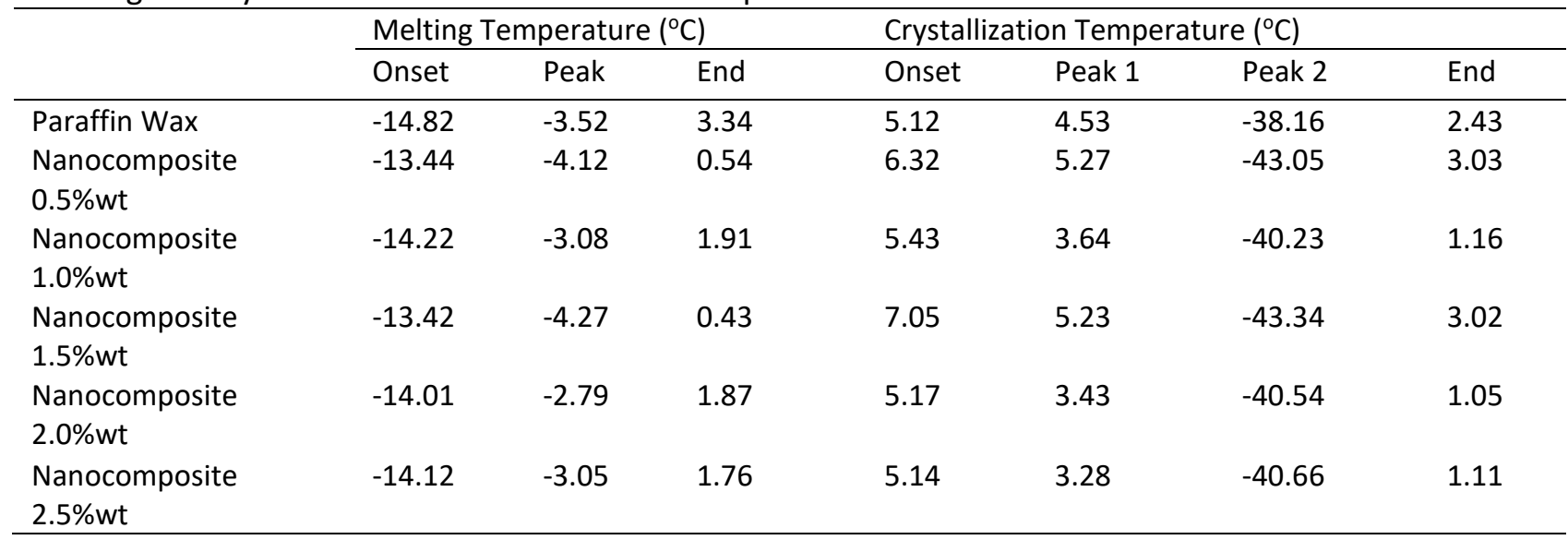

\subsection{Theoretical Models Comparison}

Thermal conductivity of $\mathrm{Cu}$ nanocomposite PCMs were determined using various models was used to determine the thermal conductivity of the nanocomposite PCM and the effect of $\mathrm{Cu} \%$ wt. added to the composite PCM. A comparison between experimental values of thermal conductivity with the values predicted by the Maxwell, Hamilton Crossover, Jeffery and Bruggeman models for nanocomposite PCMs were illustrated in Table 4.

Firstly, the thermal conductivity of the nanocomposite was calculated using the Maxwell model. Table 4, there was a slight improvement in thermal conductivity for nanocomposite PCM comparing to pure PCM. The thermal conductivities of composite PCMs with $0.5,1,1.5,2$ and $2.5 \mathrm{wt} \%$ of $\mathrm{Cu}$ determined as $0.2568,0.2593,0.2582,0.2601$ and $0.2624 \mathrm{~W} /(\mathrm{m} . \mathrm{K})$, respectively. Hamilton and Crosser is another important model used for determining the thermal conductivity of nanocomposite PCM. As it can be observed from the data, the improvement of thermal conductivity of nanocomposite PCM was noticeable, however, the improvement was not proportional to the additives of Cu nanoparticles to the PCM composite. Thermal conductivities of composite PCMs with $0.5,1,1.5,2$ and $2.5 \mathrm{wt} . \%$ of $\mathrm{Cu}$ are calculated as $0.2634,0.2677,0.2698,0.2681$ and $0.2696 \mathrm{~W} / \mathrm{m} \mathrm{K}$, respectively. Moreover, the Jeffery model was used to determine the thermal conductivity of nanocomposite PCM.

From measured data, the thermophysical values were co-linear, unlike the model values that show a linear increment for the nanocomposite PCM with increase $\mathrm{Cu}$ additive. The optimal thermal conductivity achieved was at $2.5 \mathrm{wt} . \%$ of $\mathrm{Cu}$ nanoparticles and caused enhancement of $65 \%$. The Bruggeman model was an effective model to determine the thermal conductivity of nanocomposite $\mathrm{PCM}$. The obtained results using this model shows that the thermal conductivity of nanocomposite increases remarkably with the increasing volume fraction of Cu nanoparticles. Data shows that, the thermal conductivities of composite PCMs with $0.5,1,1.5,2$ and 2.5 wt.\% of $\mathrm{Cu}$ are 0.5361, 0.5879, $0.6321,0.6498$ and $0.6543 \mathrm{~W} /(\mathrm{m} \mathrm{K})$, respectively. 
Table 4

Comparison of measured and predicted thermal conductivity $(\lambda / W m-1 \mathrm{k}-1)$, data

\begin{tabular}{|c|c|c|c|c|c|}
\hline \multirow[b]{2}{*}{ Sample } & \multicolumn{5}{|c|}{ Thermal Conductivity $\left(\lambda / \mathrm{Wm}^{-1} \mathrm{k}^{-1}\right)$} \\
\hline & Experimental & $\begin{array}{l}\text { Maxwell } \\
\text { model }\end{array}$ & $\begin{array}{l}\text { Hamilton Crossover } \\
\text { model }\end{array}$ & $\begin{array}{l}\text { Jeffery } \\
\text { model }\end{array}$ & $\begin{array}{l}\text { Bruggeman } \\
\text { model }\end{array}$ \\
\hline $\begin{array}{l}\text { PCM } \\
\text { Paraffin }\end{array}$ & 0.2483 & $\mathrm{n} / \mathrm{a}$ & $\mathrm{n} / \mathrm{a}$ & $\mathrm{n} / \mathrm{a}$ & $\mathrm{n} / \mathrm{a}$ \\
\hline $\begin{array}{l}\text { PCM } \\
\text { nanocomposite } \\
0.5 \% \text { wt }\end{array}$ & 0.3189 & 0.2568 & 0.2634 & 0.3245 & 0.5361 \\
\hline $\begin{array}{l}\text { PCM } \\
\text { nanocomposite } \\
1.0 \% \text { wt }\end{array}$ & 0.3227 & 0.2593 & 0.2677 & 0.3267 & 0.5879 \\
\hline $\begin{array}{l}\text { PCM } \\
\text { nanocomposite } \\
1.5 \% \text { wt }\end{array}$ & 0.3301 & 0.2582 & 0.2698 & 0.3302 & 0.6321 \\
\hline $\begin{array}{l}\text { PCM } \\
\text { nanocomposite } \\
2.0 \% \text { wt }\end{array}$ & 0.3398 & 0.2601 & 0.2681 & 0.3345 & 0.6498 \\
\hline $\begin{array}{l}\text { PCM } \\
\text { nanocomposite } \\
2.5 \% \text { wt }\end{array}$ & 0.3492 & 0.2624 & 0.2696 & 0.3366 & 0.6543 \\
\hline
\end{tabular}

\section{Conclusion}

Summarily, the addition of nanoparticles significantly enhances the phase transition of the PCM. Copper/paraffin composite phase change materials with different concentrations $(0.51,1.5,2$ and $2.5 \mathrm{wt} . \%)$ were prepared by a two-step method. The prepared nanocomposite showed a significant increase in heat transfer rate and thermal conductivity. The results show that as the mass concentration of $\mathrm{Cu}$ nanoparticles increases, the thermal conductivity of $\mathrm{Cu} /$ paraffin composites increases linearly. The addition of 2.5 wt.\% copper nanoparticles to the paraffin PCM composite material resulted in a $39 \%$ increase in thermal conductivity. The infrared monitoring experiments show that more intensive heat transfer occurs in $\mathrm{Cu}$ /paraffin, because of the combination of paraffin with Cu nanoparticles, which had a high thermal conductivity.

The long-term performance analysis for the latent heat and melting point of the developed $\mathrm{Cu} /$ paraffin PCM nanocomposites proved good thermal reliability in proposed applications even after 150 heating cycles. The infrared monitoring experiments show that more intensive heat transfer occurs in $\mathrm{Cu} /$ paraffin, because of the combination of paraffin with Cu nanoparticles, which had a high thermal conductivity. Also, specific heat and thermal diffusivity have been enhanced by approximately $16 \%$ and $9 \%$, respectively. Moreover, the thermal conductivity of nanocomposite PCM was compared with different theoretical models such as Maxwell mode, Hamilton Crossover model, Jeffery model, and Bruggeman model. The result shows a good agreement between the experimental values and calculated ones. DCS analysis shows that. by adding more Cu nanoparticles, the melting temperature increased to $135.32^{\circ} \mathrm{C}, 143.97^{\circ} \mathrm{C}, 151.23^{\circ} \mathrm{C}$ and $189.32^{\circ} \mathrm{C}$ for $1.0 \%$ Paraffin/ $\mathrm{Cu}, 1.5 \%$ Paraffin/ $\mathrm{Cu}, 2.0 \%$ Paraffin/ $\mathrm{Cu}$ and $2.5 \%$ Paraffin/ $\mathrm{Cu}$, respectively. Among the different mass concentration of $\mathrm{Cu}$ nanoparticles added to PCM composite, the study proved that 
the highest enhancement for PCM nanocomposite was achieved with $2.5 \%$ wt additive of $\mathrm{Cu}$ nanoparticles which make it the optimum mass fraction for the nanocomposite PCM. Based on the observation and analysis, the presented thesis fulfils most of the benchmarked objectives of this research work. Application of these nanocomposites will accomplish an environment friendly and cheaper solution to the rising demands of energy. Its application can be home heating and cooling, seasonal heat storage, waste heat recovery system and more.

\section{Conflict of Interest}

The author(s) declared no potential conflicts of interest concerning the research, authorship, and/or publication of this article.

\section{Acknowledgements}

The corresponding author acknowledges the Research Management Centre, (RMC), Universiti Tun Hussein Onn Malaysia for the financial support under the RMC Research Fund (K-200).

\section{References}

[1] Lefebvre, Dominique, and F. Handan Tezel. "A review of energy storage technologies with a focus on adsorption thermal energy storage processes for heating applications." Renewable and Sustainable Energy Reviews 67 (2017): 116-125. https://doi.org/10.1016/i.rser.2016.08.019

[2] Jahan, Sultana, M. Ferdows, M. D. Shamshuddin, and Khairy Zaimi. "Effects of Solar Radiation and Viscous Dissipation on Mixed Convective Non-Isothermal Hybrid Nanofluid over Moving Thin Needle." Journal of Advanced Research in Micro and Nano Engineering 3, no. 1 (2021): 1-11.

[3] $\mathrm{Xu}, \mathrm{Bo}$, Jiaxin $\mathrm{Xu}$, and Zhenqian Chen. "Heat transfer study in solar collector with energy storage." International Journal of Heat and Mass Transfer 156 (2020): 119778. https://doi.org/10.1016/j.ijheatmasstransfer.2020.119778

[4] Prajapati, Deepak G., and Balasubramanian Kandasubramanian. "Biodegradable polymeric solid framework-based organic phase-change materials for thermal energy storage." Industrial \& Engineering Chemistry Research 58, no. 25 (2019): 10652-10677. https://doi.org/10.1021/acs.iecr.9b01693

[5] Krope, J., A. Ghani Olabi, D. Goričanec, and S. Božičnik. "A Comprehensive Review of Solar Thermal Energy Storage." In 10TH International Conference on Sustainable Energy and Environmental Protection Energy Storage. 2017.

[6] Khyad, A., H. Samrani, and M. N. Bargach. "State of the art review of thermal energy storage systems using PCM operating with small temperature differences: Focus on Paraffin." J. Mater. Environ. Sci 7, no. 4 (2016): 1184-1192.

[7] Abdalla, Abakar Yousif, Zwalnan Selfa Johnson, Shanmugam Anandan, Chan Andy Tak-Yee, and Su Yuehong. "A Numerical Evaluation of the Effect of Building Thermal Load on the Overall Performance Characteristic of a GridCoupled PV/T Energy System." Journal of Advanced Research in Numerical Heat Transfer 4, no. 1 (2021): 32-43.

[8] Lizana Moral, Francisco Jesús, Ricardo Chacartegui, Ángela Barrios Padura, and José Manuel García Valverde. "Characterization of thermal energy storage materials for buildings applications." In Proceedings of the 3rd International Congress on Sustainable Construction and Eco-Efficient Solutions.(2017), p 606-637. Universidad de Sevilla. Escuela Técnica Superior de Arquitectura., 2017.

[9] Pelay, Ugo, Lingai Luo, Yilin Fan, Driss Stitou, and Mark Rood. "Thermal energy storage systems for concentrated solar power plants." Renewable and Sustainable Energy Reviews 79 (2017): 82-100. https://doi.org/10.1016/j.rser.2017.03.139

[10] Magendran, Suhanyaa S., Fahad Saleem Ahmed Khan, N. M. Mubarak, Mahesh Vaka, Rashmi Walvekar, Mohammad Khalid, E. C. Abdullah, Sabzoi Nizamuddin, and Rama Rao Karri. "Synthesis of organic phase change materials (PCM) for energy storage applications: A review." Nano-structures \& Nano-objects 20 (2019): 100399. https://doi.org/10.1016/i.nanoso.2019.100399

[11] Sarbu, loan, and Alexandru Dorca. "Review on heat transfer analysis in thermal energy storage using latent heat storage systems and phase change materials." International journal of energy research 43, no. 1 (2019): 29-64. https://doi.org/10.1002/er.4196

[12] Singh, Suman, Kirtiraj K. Gaikwad, and Youn Suk Lee. "Phase change materials for advanced cooling packaging." Environmental Chemistry Letters 16, no. 3 (2018): 845-859. https://doi.org/10.1007/s10311-018-0726$\underline{7}$

[13] Raval, Harshil, Jatin Patel, and Anurag Mudgal. "A Review on Enhancement of Thermophysical Properties of Paraffin Wax PCM With Nanomaterials." In ICTEA: International Conference on Thermal Engineering, vol. 2019. 2019. 
[14] Shah, Kwok Wei. "A review on enhancement of phase change materials-A nanomaterials perspective." Energy and buildings 175 (2018): 57-68. https://doi.org/10.1016/j.enbuild.2018.06.043

[15] Zou, Deqiu, Xianfeng Ma, Xiaoshi Liu, Pengjun Zheng, and Yunping Hu. "Thermal performance enhancement of composite phase change materials (PCM) using graphene and carbon nanotubes as additives for the potential application in lithium-ion power battery." International Journal of Heat and Mass Transfer 120 (2018): 33-41. https://doi.org/10.1016/j.ijheatmasstransfer.2017.12.024

[16] Parameshwaran, R., K. Deepak, R. Saravanan, and S. Kalaiselvam. "Preparation, thermal and rheological properties of hybrid nanocomposite phase change material for thermal energy storage." Applied energy 115 (2014): $320-330$. https://doi.org/10.1016/i.apenergy.2013.11.029

[17] Shin, Donghyun, and Debjyoti Banerjee. "Enhanced thermal properties of SiO2 nanocomposite for solar thermal energy storage applications." International Journal of Heat and Mass Transfer 84 (2015): 898-902. https://doi.org/10.1016/i.ijheatmasstransfer.2015.01.100

[18] Warzoha, Ronald J., Anthony Rao, Rebecca Weigand, and Amy S. Fleischer. "Experimental characterization of the thermal diffusivity of paraffin phase change material embedded with herringbone style graphite nanofibers." In Heat Transfer Summer Conference, vol. 44786, pp. 307-315. American Society of Mechanical Engineers, 2012. https://doi.org/10.1115/HT2012-58043

[19] Saeed, Rami M., Joshua P. Schlegel, C. Castano, and R. Sawafta. "Preparation and enhanced thermal performance of novel (solid to gel) form-stable eutectic PCM modified by nano-graphene platelets." Journal of Energy Storage 15 (2018): 91-102. https://doi.org/10.1016/j.est.2017.11.003

[20] Sarbu, Ioan, and Calin Sebarchievici. "A comprehensive review of thermal energy storage." Sustainability 10, no. 1 (2018): 191. https://doi.org/10.3390/su10010191

[21] Harun, Muhammad Amin, Zafri Azran Abdul Majid, Zairul Azrul Zakaria, Ahmad Faris Ismail, Sany Izan Ihsan, Kamaruzzaman Sopian, Ahmad Fadzil Sharol, and Amir Abdul Razak. "Study on Selection of a Suitable Material and The Parameters for Designing a Portable Flat Plate Base-Thermal Cell Absorber (FPBTCA)." Journal of Advanced Research in Fluid Mechanics and Thermal Sciences 85, no. 1 (2021): 71-92. https://doi.org/10.37934/arfmts.85.1.7192 